\title{
NEURAL CREST STEM CELL POPULATION IN CRANIOMAXILLOFACIAL DEVELOPMENT AND TISSUE REPAIR
}

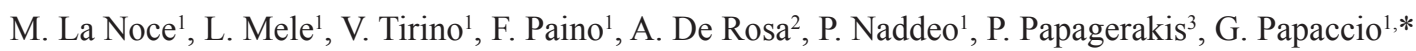 \\ and V. Desiderio ${ }^{1}$
}

\author{
${ }^{1}$ Dipartimento di Medicina Sperimentale, Sezione di Biotecnologie, Istologia Medica e Biologia Molecolare, \\ Secondo Ateneo di Napoli, Naples, Italy \\ ${ }^{2}$ Dipartimento Multidisciplinare Medico-Chirurgico, Sezione di Odontoiatria, Secondo Ateneo di Napoli, \\ Naples, Italy \\ ${ }^{3}$ Department of Orthodontics and Pediatric Dentistry, Center for Organogenesis, School of Dentistry, \\ University of Michigan, Ann Arbor, MI, USA
}

\begin{abstract}
Neural crest cells, delaminating from the neural tube during migration, undergo an epithelial-mesenchymal transition and differentiate into several cell types strongly reinforcing the mesoderm of the craniofacial body area - giving rise to bone, cartilage and other tissues and cells of this human body area. Recent studies on craniomaxillofacial neural crest-derived cells have provided evidence for the tremendous plasticity of these cells. Actually, neural crest cells can respond and adapt to the environment in which they migrate and the cranial mesoderm plays an important role toward patterning the identity of the migrating neural crest cells. In our experience, neural crest-derived stem cells, such as dental pulp stem cells, can actively proliferate, repair bone and give rise to other tissues and cytotypes, including blood vessels, smooth muscle, adipocytes and melanocytes, highlighting that their use in tissue engineering is successful. In this review, we provide an overview of the main pathways involved in neural crest formation, delamination, migration and differentiation; and, in particular, we concentrate our attention on the translatability of the latest scientific progress. Here we try to suggest new ideas and strategies that are needed to fully develop the clinical use of these cells. This effort should involve both researchers/clinicians and improvements in good manufacturing practice procedures. It is important to address studies towards clinical application or take into consideration that studies must have an effective therapeutic prospect for humans. New approaches and ideas must be concentrated also toward stem cell recruitment and activation within the human body, overcoming the classical grafting.
\end{abstract}

Keywords: Neural crest, CMF, development, differentiation, tissue engineering, translational medicine.

*Address for correspondence:

Prof. Dr. Gianpaolo Papaccio

Dipartimento di Medicina Sperimentale

Sezione di Istologia ed Embriologia

Secondo Ateneo di Napoli

5 via L. Armanni

80138 Napoli, Italy

Telephone Number: +39 0815666014/7720

FAX Number: +390815666014

E-mail: gianpaolo.papaccio@unina2.it

\section{Introduction}

The neural crest, a distinctive transient embryonic cell population, was initially identified by the Swiss embryologist Wilhelm His in 1868 as "the intermediate cord" (Zwischenstrang) because of its origin between the neural plate and non-neural ectoderm in the neurula-stage chick embryo. In a paper on the development of the cranial nerves in chick embryos, Marshall (1879) used the term neural ridge for the cells that give rise to cranial and spinal nerve ganglia. Realising that this term was less descriptive than was desirable, a year later he swapped neural ridge with neural crest. The neural crest has been called the "fourth germ layer", because of its importance. Indeed, it is a multipotent tissue that gives rise to various differentiated cell types in the adult organism, and is unique to vertebrate embryos (Thorogood, 1989).

The induction of the neural crest begins during neurulation, when the borders of the neural plate, also known as the neural folds, converge at the dorsal midline to form the neural tube. This, subsequently, becomes covered by future epidermal ectoderm. Neural crest cells are positioned on the top (dorsal) edges of the forming neural folds. Once the neural tube has closed, the neural crest cells form a distinct population of cells resting on top of the neural tube. The interaction between the neural plate and the epidermal ectoderm causes the induction of the neural crest cells, which migrate from the dorsal neural tube - along defined pathways - to a number of sites at which they stop migrating. During migration, cells undergo an epithelial-mesenchymal transition and differentiate into a very wide range of derivatives. These include skin pigment cells (melanocytes and other pigments), neurons of the dorsal root ganglia of spinal nerves, the autonomic nervous system (both sympathetic and parasympathetic ganglia), Schwann cells responsible for myelination of peripheral nerves, pericytes and smooth muscle cells of the vascular system, including the major vessels of the heart, the adrenal medulla and leptomeninges (Smith and Schoenwolf, 1989; Keller et al., 1992). Neural crest cells are also important in the pharyngeal arches and head, forming some bones and cartilage in the lower jaw as well as portions of the eyes, ears and teeth.

Given the wide variety of differentiation fates and the capacity for self-renewal, neural crest cells are often considered to be a stem-cell-like population. In fact, the neural crest can generate a great variety of cell and tissue 
types and for this reason represents a multipotent cell population. The "stemness" of neural crest cells is shown by experiments that revealed that, in vivo at least, some neural crest cells give rise to multiple cell types including neurons, smooth muscle and melanocytes (Bronner-Fraser and Fraser, 1989; Frank and Sanes, 1991). The term "NCSCs" (neural crest stem cells) was coined by Stemple and Anderson when showing that in vitro neural crest cells not only have the ability to give rise to autonomic neurons, glia and smooth muscle, but also to self-renew, a unique characteristic of stem cells (Stemple and Anderson, 1992).

\section{Neural Crest Formation: Induction, Delamination and Migration}

The complete induction of neural crest cells is a complex process that involves the activity of extracellular factors produced by the inductive tissues that activate a genetic program in the ectodermal cells. Once this genetic program is activated in the neural crest cells, a second set of genes, the proper neural crest genes, are transcribed. One of the important functions of this second set of genes is to allow survival (or maintenance) of the recently induced neural crest cells. Finally, the two set of genes work together to control delamination, migration and differentiation of the neural crest cells (Morales et al., 2005).

\section{Induction}

The induction of neural crest is a multistep process, starting at the early gastrula stage and continuing until neural tube closure. Several studies have concentrated on the identification of the signalling molecules involved in the induction of the neural crest. The signals that activate neural crest cells are released from the neural plate, the epidermis and the lateral mesoderm. At least four distinct signalling pathways have been implicated in this process in different species. These include bone morphogenetic proteins (BMP), Wnts, fibroblast growth factors (FGF), and more recently the Notch/Delta signalling pathways (Huang and Saint-Jeannet, 2004; Klymkowsky et al., 2010).

The two members of the BMP family involved in the inductive process are BMP-4 and BMP-7 and are expressed by the epidermal ectoderm. They elicit the formation and migration of neural crest cells from the neural plate. Findings led to the proposal of a model in which the different fates of the ectoderm derivatives are specified by a gradient in BMP activity (Graham, 2003). The upstream factors that control BMP-4 expression and restrict the generation of neural crest cells to the neural and non-neural ectoderm boundary have recently been identified and are involved in the Delta/Notch pathway. Moreover, several studies suggest that other signals are required, in addition to BMPs, in order to induce the neural crest. A much more robust induction occurred when inhibition of BMP signalling was accompanied by exposure to Wnts or FGFs (Sasaki et al., 2006; Monsoro-Burq et al., 2003). Several lines of evidence suggest that members of the Wnt family of secreted glycoproteins can act as neural crest inducers (Mayor et al., 1997; LaBonne and Bronner-Fraser, 1998).

\section{Delamination and migration}

Once specified, neural crest cells must delaminate from the neural tube to migrate to their destinations and undergo a transition from the epithelial to the mesenchymal type (Nieto, 2001). During the entire process of neural crest development, neural crest cells undergo a series of transformations that include the modification of their cellcell and cell-substrate adhesion properties, improving their migration capability (Duband, 2006).

At the beginning of neural tube formation, nascent neural crest cells remain integrated at the dorsal side of the neural tube and are morphologically indistinguishable from other neural epithelial cells (Achilleos and Trainor, 2012). At the end of the delamination step, crest cells are clearly distinct from neural tube cells and can be recognise both molecularly and morphologically. Indeed, neural crest cells are regular, elongated and radially oriented, and become first more rounded and irregular in shape, and then, when they are completely separated from the neural tube, they flatten over the surface of the neural tube and extend tangentially to it. In addition, alterations in cellular adhesion also occur: E-cadherin is replaced by $\mathrm{N}$-cadherin and cadherin-6B, until onset of migration. Subsequently, after their complete exclusion from the neural epithelium, neural crest cells lose $\mathrm{N}$-cadherin and cadherin-6B expression. Finally, migrating neural crest cells start expressing cadherin-7 and/or cadherin-11, two types of cadherin expressed by fibroblasts (Duband, 2006).

Changes in the interaction with the extracellular matrix also occur, favouring the release of these cells from the neural tube. Several in vitro studies have indicated that Rho-B, a member of the rho family GTP-binding proteins that control cell adhesion and motility through dynamic regulation of the actin cytoskeleton, plays a specific role in the control of neural crest delamination (Tondeleir et al., 2014).

There are opposing views about the role of Slug in neural crest delamination: in fact, some studies affirm that it plays a fundamental role, while others state that, at certain axial levels, it is neither necessary nor sufficient. More recently, using an inducible inhibitory mutant, Slug was found to be involved in the formation of neural crest precursors and in neural crest migration (LaBonne and Bronner-Fraser, 2000). Since one of the first events for an epithelial cell to become migratory is the loss of cell-to-cell adhesion molecules, it was suggested that targets of Slug could be molecules such as cadherins. It was demonstrated that an overexpression of a neuroepithelial cadherin or a crest cadherin in the neural tube impaired neural crest emigration (Theveneau and Mayor, 2012). This indicated that fine regulation of cadherin expression is fundamental for the emigration of the neural crest from the neural tube (Nieto, 2001).

Upon migrating from the dorsal surface of the neural tube, neural crest cells enter a cell-free zone that is rich in extracellular matrix molecules. Although they are readily detectable in this cell-free zone, they soon become morphologically indistinguishable from tissues through which they migrate. The migration begins cranially and gradually extends caudally. The overall migration can 
be summarised by three pathways: a ventral pathway, a lateral pathway and a dorsal route. Cells that go around the notochord and neural tube characterise the ventral pathway (Cerny et al., 2004).

Cessation of migration is not a simple process. Some cessation processes involve increasing the production of chondroitin sulphate and decreasing the amount of collagen and other substrates. The chondroitin sulphate and aggrecan-rich extracellular matrix encountered by deeply migrating neural crest cells inhibits the formation of cell-to-cell attachments so that neural crest cells migrate as single cells. Consequently, chondroitin sulphate and other glycoconjugates provide barriers to crest cell migration. Other parts of the embryo (notochord) secrete substances, such as trypsin- and chondroitinase-labile molecules, that make migration difficult. Migrating neural crest cells influence the patterning of other cell types.

\section{Neural Crest Domains}

Neural crest cells originating from different positions along the anterior-posterior axis develop into various tissues. The regions of the neural crest can be divided into four main functional domains, which include the craniomaxillofacial (CMF) neural crest, trunk neural crest, vagal and sacral neural crest, and cardiac neural crest. Each domain responds to specific migration and differentiation signals to generate the appropriate cells and tissues (Taneyhill, 2008). In this review we will concentrate on CMF neural crest-derived cells.

\section{Craniomaxillofacial neural crest}

The vertebrate head is a complex assemblage of cranial specialisations, including the central and peripheral nervous systems, viscero- and neuro-cranium, musculature and connective tissue. The primary differences that exist between vertebrates and other chordates relate to their craniofacial organisation. Therefore, the evolution of the head is considered fundamental to the origins of vertebrates (Gans and Northcutt, 1983).

In the 1890s, Julia Platt claimed that the cartilage of the craniofacial area, the pharyngeal arch skeletons and the dentine-forming cells (odontoblasts) of the teeth of the mudpuppy, Necturus maculosus, arose from the ectoderm adjacent to the neural tube (Platt, 1893, 1894, 1897). Platt's results were extremely controversial as they ran counter to the prevailing germ layer theory of the day, and her hypothesis of the cranial skeletogenic origin of the neural crest only truly gained acceptance 50 years later, primarily through the seminal work of Sven Horstadius (Horstadius, 1950).

The cranial neural crest (CNC) consists of several populations that differ in their migratory pathways, patterns of gene expression, and types of derivatives. For functional purposes, $\mathrm{CNC}$ cells can be subdivided into regions designated here as caudal forebrain, midbrain, rostral hindbrain and caudal hindbrain (which overlaps with rostral vagal) neural crest cells. Each population has a somewhat different pattern of migration and prospective derivatives. At the midbrain level, $\mathrm{CNC}$ cells emerge and migrate primarily as a broad, unsegmented sheet of cells under the ectoderm. These cells contribute to a wide range of derivatives that include the periocular skeleton, connective tissue of the eye, membrane bones of the face, ciliary ganglion, part of the trigeminal ganglion and Schwann cells (Le Douarin and Kalcheim, 1999).

The hindbrain is a unique region of the neural tube because it is the only portion of the developing brain that is overtly segmented. It is subdivided into eight segments or rhombomeres. Rhombomeres represent compartments of lineage restriction such that clones of cells do not cross rhombomere boundaries (Fraser et al., 1990). Hindbrain neural crest cells migrate in a segmental fashion as three broad streams emanating laterally adjacent to rhombomeres (r) rl, r2, r4 and r6, with no CNC cells apparent at the level of $\mathrm{r} 3$ or $\mathrm{r} 5$. The first of these streams populates the trigeminal ganglion and mandibular arch; the second populates the hyoid arch, as well as the geniculate and vestibular ganglia; the third stream populates the third and fourth branchial arches and associated peripheral ganglia. The DiI-labelling experiments of Lumsden and colleagues suggested that $\mathrm{r} 3$ and $\mathrm{r} 5$ do not form neural crest cells, consistent with the possibility that the segmental migratory pattern reflects a patterned origin within the neural tube (Noden, 1975; Lumsden et al., 1991).

Because of the difficulties in culturing embryos, microsurgical manipulation of embryonic tissue and maintaining the dye throughout the long period of embryogenesis, it was not possible to obtain a systematic lineage analysis of neural crest cell derivatives in mammals. The biological function of these CNC-derived cells has been studied in a variety of animal models and two possible theories have been put forth: first, these neural crest cells may carry certain pre-acquired molecular signals as they migrate into the branchial arch so they can induce epithelium to form various craniofacial structures (Woo and Fraser, 1998; Artinger et al., 1999); second, CNC cells acquire positional identity at the time they reach their final destination and contribute to the formation of various craniofacial structures. Certain growth and transcription factors have been implicated as important regulators for the critical epithelial-mesenchymal interactions. These factors stimulate multipotent neural crest-derived cells to form neural crest derivatives and to differentiate in specific tissue cells (Thesleff and Sharpe, 1997; Saldivar et al., 1997; Tucker et al., 1999).

\section{Molecular Basis and Gene Involvement}

Some understanding of the molecular basis of hindbrain and neural crest specification has come from analyses of the expression and function of Hox homeobox genes, homologues of the homeotic genes of Drosophila. Each Hox gene is expressed in an overlapping domain along the anterior-posterior axis of the embryo, but each gene has a characteristic segmental limit of expression at its anterior boundary. In the developing head, this spatially restricted expression pattern is seen in the hindbrain, with the anterior limits of Hox gene expression corresponding to rhombomere boundaries at two-segment intervals. As the 
neural crest migrates from the rhombomeres into specific branchial arches, it retains the particular combination or code of Hox gene expression that is characteristic of the rhombomeres from which it originated. Thus, the neural crest from each axial level conveys a unique combinatorial Hox code. This code can be considered to specify form and pattern for the different branchial arch-derived regions of the head and neck (Hunt et al., 1991a).

Another gene that may be involved in segmental patterning, both in the hindbrain and neural crest, is the zinc finger gene Krox-20. Krox-20 is expressed in alternating domains in the neural plate that later correspond to $\mathrm{r} 3$ and r5, where it acts as a transcriptional regulator of HoxB2 expression (Sham et al., 1993). In addition to its expression in r3 and r5, Krox-20 is detectable in neural crest precursors in the dorsal midline of the neural tube extending from caudal r5 into r6. These Krox-20-expressing cells leave the neural tube at the 13 -somite stage, emerging near the $\mathrm{r} 5 / 6$ border and migrating caudally and ventrally. By combining DiI cell marking techniques with in situ hybridisation (Izpisua-Belmonte et al., 1993), it was possible to determine the rhombomeric origin of some neural crest cells that carry the Krox-20 transcription factor (Nieto et al., 1991). The results showed that both $\mathrm{r} 5$ and r6 contributed to the Krox-20-expressing neural crest cells that migrate caudally around the otic vesicle. Krox-20expressing cells first migrate from mid-to-caudal r6 and shortly thereafter from rostral $\mathrm{r} 6$ and $\mathrm{r} 5$. Its expression is transient, becoming undetectable in the neural crest by the 23-somite stage (Bronner-Fraser, 1994).

Goosecoid is another homeobox-containing transcription factor, originally isolated in Xenopus from a dorsal blastopore lip cDNA library. The dorsal blastopore lip has long been known to be ultimately responsible for organisation of the complete body axis in the early embryo. However, when goosecoid was knocked out in transgenic mice, the body axis was formed normally but the embryos exhibited a number of craniofacial defects (Rivera-Pérez et al., 1995; Yamada et al., 1995). In wild type mice, goosecoid transcripts were detected at later stages of development in the osteogenic mesenchyme of the developing mandible, tongue and middle ear. In the mutants, the mandible was hypoplastic and lacked coronoid and angular processes, whilst there were defects in several bones, including the maxillary, palatine and pterygoid. As a homeobox-containing transcription factor, it would appear that goosecoid is involved in essential inductive tissue interactions during formation of the head, but has a redundant function in the mouse gastrula organiser.

Another gene that has produced an even more perplexing phenotype is endothelin-1 (ET-1). Endothelin-1 encodes a vasoactive peptide expressed in vascular endothelial cells and is thought to play a role in the regulation of blood pressure. Mice with targeted disruption of ET-1 had no abnormalities in their cardiovascular system but did have a marked reduction in tongue size, micrognathia and cleft palate (Kurihara et al., 1994). Components of the ET pathway are now known to be involved in development of the cephalic neural crest. One of the two G proteincoupled endothelin receptors, ET-A, is expressed in the neural crest-derived ectomesenchyme of the branchial arches, whilst its primary ligand, ET-1, is expressed in arch epithelium, pharyngeal pouch endothelium and arch core paraxial mesoderm. The ET-A/ET-1 pathway appears to be important for proper patterning of the caudal regions of the first arch (Tucker et al., 1999). Targeted disruption of ET-A or ET-1 in mice produced craniofacial defects that resembled a human condition called $\mathrm{CATCH}-22$, which is characterised by abnormal facies and cardiovascular defects (Wilson et al., 1993). It has recently been shown that the craniofacial defects in the $E T-A^{-/}$mice are, in part, due to an absence of the goosecoid transcription factor (Clouthier et al., 1998).

Another important pathway involved in craniofacial development is kinin-kallikrein signalling. This is active in a particular region highly conserved of embryos of Xenopus and zebrafish, defined extreme anterior domain (EAD) including mouth. Deregulation of this pathway, leads to the failure of forming the mouth and to abnormal development and migration of the neural crest (Jacox et al., 2014).

The classical view of craniofacial development and neural crest patterning, was that regional diversity in the vertebrate head was a consequence of patterning information provided by the neural crest (Noden, 1983; Hunt et al., 1991b).

\section{Craniomaxillofacial Patterning Advanced Studies}

Recently, there have been significant advances in our understanding of craniofacial patterning through neural crest cell transpositions within the hindbrains of mice (Golding et al., 2000; Trainor and Krumlauf, 2000) and zebrafish embryos (Schilling et al., 2001). In contrast to the classic analyses performed in avian embryos, these new studies uncovered a consistently high degree of CNC cell plasticity. In heterotopic transplantations of neural crest cells within mouse and zebrafish hindbrains, graftderived neural crest cells migrated into the nearest arch without any evidence of path finding; concomitantly, there was inappropriately downregulated Hox gene expression in these cells (Trainor and Krumlauf, 2000). In zebrafish embryos, the transplanted cells were followed for longer periods, such that the cells activated new gene expression programs and they differentiated and contributed to pharyngeal cartilage appropriate to their new axial location (Schilling, 2001). These results demonstrated that the axial character of cranial neural crest cells are neither fixed nor passively transferred from the hindbrain to the branchial arches and periphery of the head. The plasticity observed in neural crest cell patterning correlated with molecular analyses that identified distinct cis-regulatory elements controlling Hox gene expression in different tissues, such as the neural tube and neural crest (Maconochie et al., 1999). Consequently, these results supported a new model called the "neural crest plasticity and independent gene regulation model" as a mechanism for describing neural crest and craniofacial development. This argues that neural crest cells can respond and adapt to the environment in which they migrate. Furthermore, it is suggested that the cranial mesoderm plays an important role in patterning the 
identity of the migrating neural crest cells (Golding et al., 2000; Trainor and Krumlauf, 2000).

The observations described above, demonstrating that neural crest cells are plastic and that gene expression is independently regulated in different tissues of the head, provides a mechanism for how neural crest cells can be modified or evolve in response to the environment through which they migrate, independently of the neural tube from which they are derived. Although the hindbrain exerts a profound influence in establishing the foundations of vertebrate head development, a rigid neural crest pre-patterning model in which the program for head morphogenesis is set in the neural tube would offer very restricted opportunities for diversifying head structures. In contrast, the neural crest plasticity and independent gene regulation model could provide the flexibility and adaptability that facilitates diversity, and we can speculate that it might be one reason for the successful radiation of vertebrates into new environments. This is because neural crest plasticity and independent gene regulation offers the potential for generating substantially distinct cranial phenotypes by subtle, minor changes of the primordial pattern. Successful adaptation and developmental flexibility is particularly evident in the bird beak, which has undergone extensive diversification and modification during evolution. Bird beaks are used for numerous diverse functions, including eating, defence, scratching, courting and preening. Even though beak morphology is remarkably variable between species, and even within species, each beak is derived from comparable tissues during development. The lower beak is bipartite and is formed by the fusion of the paired mandibular cartilages; in contrast, the tripartite upper beak is derived from the fusion of the frontonasal mass to the paired lateral nasal and maxillary cartilages. All of the beak's cartilage and connective tissue is derived from neural crest cells (Helms and Schneider, 2003). The outer cornified layers of the beak come from the ectoderm, while the mastication/articulation muscles come from the mesoderm (Noden, 1983). Evolutionary modifications in beak morphology could be driven by any, if not all, of these tissue components. Recently, an elegant series of interspecies neural crest cell transplantations revealed that neural crest cells direct beak morphology in a species-dependent and autonomous manner (Helms and Schneider, 2003). When quail neural crest cells, which normally give rise to narrow, short beaks, were transplanted into duck hosts, the resulting chimeras exhibited beak morphologies characteristic of the quail. Conversely, when duck neural crest cells, which normally produce longer, flatter bills, were transplanted into quail hosts, the resulting chimera developed beaks typical of ducks. Interestingly, the donor neural crest cells also transformed host-derived structures. The morphology of the beak epidermis and egg tooth, and the positioning of the external nasal openings in the chimeras, were all characteristic of the species from which the neural crest cells were derived. This is despite the fact that the egg tooth and epidermis are host tissue-derived structures. Most significant, however, was the observation in the quail/duck chimeras that the spatiotemporal patterns of gene expression in the facial mesenchyme (donor derived) and the ectoderm (host derived) were always characteristic of the donor. Hence, when donor quail neural crest cells were transplanted into ducks, the chimeras exhibited accelerated gene expression programs characteristic of the quail even in tissues derived from the duck host. This demonstrated that neural crest cells pattern beak development in a species-specific manner by maintaining their own molecular programs and by regulating the patterns of gene expression and differentiation in adjacent tissues. Therefore, neural crest cells can regulate the spatial patterns of cellular differentiation around them during craniofacial development. Morphometric measurements of the beaks obtained in quail/duck chimeras revealed only minor size and shape changes. The beaks that developed in the chimeras were more characteristic of the species origin of the donor neural crest cells rather than of the host into which they were transplanted. The implication of this observation is that during evolution, the ectodermal tissues surrounding the neural crest-derived beak may influence neural crest cell differentiation only to a minor extent. This may not be that surprising given that neural crest-derived cartilage and bone, to which soft tissues such as the muscles and connective tissue must adhere, provide the scaffolding for the vertebrate head.

\section{Role of Neural-Crest-Derived Stem Cells: First Evidence in CMF Repair}

The use of human pluripotent stem cells (hPSCs) in regenerative medicine is becoming increasingly diffuse, particularly in the reconstruction of the craniomaxillofacial complex of patients with both hard and soft tissue deficits due to trauma, tumour or congenital disease. The craniomaxillofacial complex is of fundamental importance for many different functions, some of which are vital, such as breathing and eating, while others are non-vital but still important for social relationships, such as aesthetics and the delivery of senses such as sight, smell and sound. For these reasons, loss of craniomaxillofacial tissue has serious psychological consequences, so it is important to seek solutions to optimise the life of people with maxillofacial trauma or head and neck cancer (Teo and Vallier, 2010).

After neurulation, the cells of the neural crest migrate and give rise to various cell populations of the adult body. They also have the ability to self-renew. Therefore, they may be considered stem cells (Pierret et al., 2006). In the adult organism, several different tissues contain cells with a self-renewal capacity and differentiation potential resembling that of neural crest cells during embryonic development. Neural crest stem cells (NCSCs) have been described in dorsal root ganglion (DRG), gut, cornea, heart and skin (Achilleos and Trainor, 2012).

A study by Nagoshi et al. (2008) recently showed the existence of NCSCs (i.e., cells with mesenchymal and neural potential) in the bone marrow. Although their frequency drastically decreases with age, multipotent NCSCs in adult bone marrow could provide an attractive source for future cell replacement therapies. In particular, 

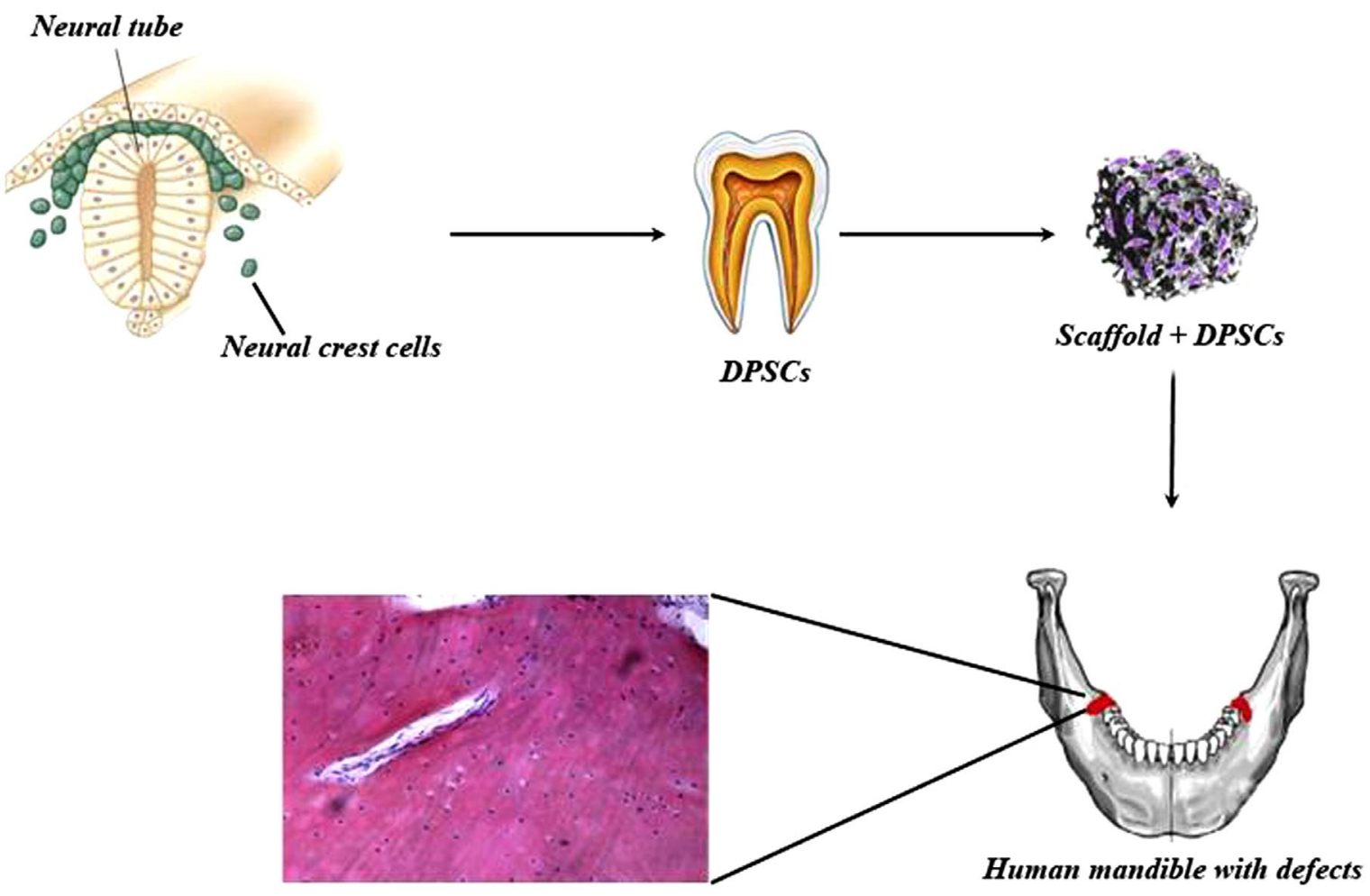

Particular: regenerated bone after three years graft

Fig. 1. Representation of human mandible defect repair using DPSCs seeded on a scaffold.

bone marrow stromal cells (BMSCs) are capable of differentiating into osteoblasts, chondrocytes, adipocytes and myoblasts (Prockop, 1997). Several studies have also shown their ability to give rise to neurons and glia in vitro and, after transplantation, in the central nervous system (Hofstetter et al., 2002; Arnhold et al., 2006). More interesting is the recent discovery that neural crest-related stem cells can be isolated from mammalian craniofacial tissues, such as dental pulp (Sasaki et al., 2008), periodontal ligaments (Widera et al., 2007; Techawattanawisal et al., 2007) and dental follicles (d'Aquino et al., 2011; Schiraldi et al., 2012) or even salivary glands (Takahashi et al., 2014). Overall, dental pulp stem cells (DPSCs) are more suitable than bone marrow mesenchymal stem cells (BMMSCs) for mineralised tissue regeneration (Alge et al., 2010).

In vivo, when transplanted into immunocompromised mice, DPSCs generated dentin-like structures (Gronthos et al., 2000) or bone (Laino et al., 2005; d'Aquino et al., 2007). In vitro, DPSCs generated adipocytes, smooth muscle cells and differentiated into functionally active neurons, as assessed by electrophysiological analysis (Arthur et $a l ., 2008)$. Moreover, it was recently demonstrated that DPSCs express proteins involved in melanogenesis at different points during their differentiation in vitro, even when they were not stimulated by a selective differentiating medium for melanocytes, demonstrating for the first time that DPSCs are capable of spontaneously differentiating into mature melanocytes (Paino et al., 2010). In addition, DPSCs were able to form capillary-like structures when cultured with VEGF (Marchionni et al., 2009).

In a clinical study, d'Aquino et al. (2009) demonstrated that a DPSC/collagen sponge bio-complex completely restored human mandible bone defects. After three years, a follow-up study (Giuliani et al., 2013) demonstrated that the regenerated bone was uniformly vascularised and qualitatively compact. This result demonstrated that DPSCs successfully repair bone. In this context (Fig. 1), compact bone regenerated after DPSC engraftments in the mandible could be considered of fundamental importance to limit pathologic fracture and to guarantee better quality of life in oral cancer patients (La Noce et al., 2014). These results demonstrated that DPSCs successfully repair bone, although the portion of the reconstructed mandible was made of compact bone instead of the expected physiological spongy bone. The latter highlights a major issue and burning question in stem cell use and grafting into patients: do the stem cells exactly reconstruct the damaged tissue and site where they are transplanted or can they divert their fate giving rise to other cells and tissues? In the reported cases, the different quality of bone was more an advantage than a disadvantage, but the issue is of paramount importance, mostly for bigger reconstructions. A further issue, which correlates with the different bone quality, is linked to the quality and quantity of stem cells needed for each grafting. 


\section{Conclusions and Perspectives}

Stem cells represent an important source in regenerative medicine. Their use in recent years has allowed us to ameliorate tissue reconstruction techniques considerably with the purpose of improving human healthcare. Damage to the craniomaxillofacial tissue resulting into scars and deformities, besides causing physical ailments, including disorders to the different sensory systems and respiratory tract, may have significant psychological consequences for the patient. The craniofacial NCSCs, owing to their ability to regenerate and support new tissues, their easy isolation and their ongoing presence in the adult organism, are good candidates for regenerative medicine in craniomaxillofacial damage.

New ideas and strategies are needed to fully develop the potential for clinical applications of these cells. This effort should involve both researchers/clinicians and improvements in good manufacturing practice (GMP) procedures/rules. It is important to address studies towards clinical application or, at least, keep in consideration that all studies must have an effective therapeutic prospect for humans. The GMP procedures that must be followed by researchers/clinicians, even for the engraftment of autologous cells, are often difficult to follow and need to be simplified by the use of new technologies. The latter will probably reduce the gap existing between stem cell research, which has expanded at an exponential rate, and its therapeutic applications that have progressed much more slowly.

In the next few years, the targets of cell therapy will be to identify and understand cell differentiation mechanisms, so that optimal cell populations and culture conditions can be used in a more efficient treatment of disease; it is also important to evaluate the role of specific and new molecules that recruit endogenous stem cells for tissue regeneration. This strategy is hopefully an easier way towards a clinically acceptable procedure. Therefore, we expect that increased application of stem cells will strengthen the translatability to supporting clinical trials.

From this point of view, it would be of great interest to study neural crest-derived stem cells and their fate, particularly in the oromaxillofacial region. Future strategies include: (i) studies devoted to understand both the quality and quantity of stem cells needed for each grafting, as it is more important to transplant less stem cells of good quality than a great number of them, which then quickly die; and (ii) studies of specific patterns that become, day by day, of major interest. In addition, it is also of importance to stimulate endogenous stem cells rather than grafting them into the patient. In this regards progress has been made by scientists and this seems to be another important future strategy to obtain tissue regeneration inside the patient's body (Arany et al., 2014).

Moreover, great importance has been given in recent years to epigenetic studies, since it is known that epigenetic regulation of gene expression can affect both the maintenance and the fate of stem cell state and the commitment to a differentiated profile (Paino et al, 2014). The use of neural crest-derived stem cells, supported by drugs that affect DNA indirectly by modifying epigenetic factors, may represent the final step in the improvement of regenerative medicine.

\section{Acknowledgements}

We wish to confirm that there are no known conflicts of interest associated with this publication and there has been no significant financial support for this work that could have influenced its outcome.

\section{References}

Achilleos A and Trainor PA (2012) Neural crest stem cells: discovery, properties and potential for therapy. Cell Research 22: 288-304.

Alge DL, Zhou D, Adams LL, Wyss BK, Shadday MD, Woods EJ, Gabriel Chu TM, Goebel WS (2010) Donormatched comparison of dental pulp stem cells and bone marrow-derived mesenchymal stem cells in a rat model. $\mathrm{J}$ Tissue Eng Regen Med 4: 73-81.

Arany PR, Cho A, Hunt TD, Sidhu G, Shin K, Hahm E, Huang GX, Weaver J, Chen AC, Padwa BL, Hamblin MR, Barcellos-Hoff MH, Kulkarni AB, J Mooney D (2014) Photoactivation of endogenous latent transforming growth factor $\beta 1$ directs dental stem cell differentiation for regeneration. Sci Transl Med 6: 238ra69.

Arnhold S, Klein H, Klinz FJ, Absenger Y, Schmidt A, Schinköthe T, Brixius K, Kozlowski J, Desai B, Bloch W, Addicks K (2006) Human bone marrow stroma cells display certain neural characteristics and integrate in the subventricular compartment after injection into the liquor system. Eur J Cell Biol 85: 551-565.

Arthur A, Rychkov G, Shi S, Koblar SA, Gronthos S (2008) Adult human dental pulp stem cells differentiate toward functionally active neurons under appropriate environmental cues. Stem Cells 26: 1787-1795.

Artinger KB, Chitnis AB, Mercola M, Driever W (1999) Zebrafish narrowminded suggests a genetic link between formation of neural crest and primary sensory neurons. Development 126: 3969-3979.

Bronner-Fraser M (1994) Neural crest cell formation and migration in the developing embryo. FASEB J 8: 699706.

Bronner-Fraser M, Fraser S (1989) Developmental potential of avian trunk neural crest cells in situ. Neuron 3: 755-766.

Cerny R, Meulemans D, Berger J, Wilsch-Bräuninger M, Kurth T, Bronner-Fraser M, Epperlein HH (2004) Combined intrinsic and extrinsic influences pattern cranial neural crest migration and pharyngeal arch morphogenesis in axolotl. Dev Biol 266: 252-269.

Clouthier DE, Hosoda K, Richardson JA, Williams SC, Yanagisawa H, Kuwaki T, Kumada M, Hammer RE, Yanagisawa M (1998) Cranial and cardiac neural crest defects in endothelin-A receptor-deficient mice. Development 125: 813-824.

d'Aquino R, Graziano A, Sampaolesi M, Laino G, Pirozzi G, De Rosa A, Papaccio G (2007) Human postnatal dental pulp cells co-differentiate into osteoblasts and 
endotheliocytes: a pivotal synergy leading to adult bone tissue formation. Cell Death Differ 14: 1162-1171.

d'Aquino R, De Rosa A, Lanza V, Tirino V, Laino L, Graziano A, Desiderio V, Laino G, Papaccio G (2009) Human mandible bone defect repair by the grafting of dental pulp stem/progenitor cells and collagen sponge biocomplexes. Eur Cell Mater 18: 75-83.

d'Aquino R, Tirino V, Desiderio V, Studer M, De Angelis GC, Laino L, De Rosa A, Di Nucci D, Martino S, Paino F, Sampaolesi M, Papaccio G (2011) Human neural crest-derived postnatal cells exhibit remarkable embryonic attributes either in vitro or in vivo. Eur Cell Mater 21: 304 316.

Duband JL (2006) Neural crest delamination and migration: integrating regulations of cell interactions, locomotion, survival and fate. Adv Exp Med Biol 589: 45-77.

Frank E, Sanes JR (1991) Lineage of neurons and glia in chick dorsal root ganglia: analysis in vivo with a recombinant retrovirus. Development 111: 895-908.

Fraser S, Keynes R, Lumsden A (1990) Segmentation in the chick embryo hindbrain is defined by cell lineage restrictions. Nature 344: 431-435.

Gans C, Northcutt RG (1983) Neural crest and the origin of vertebrates: a new head. Science 220: 268-273.

Giuliani A, Manescu A, Langer M, Rustichelli F, Desiderio V, Paino F, De Rosa A, Laino L, d'Aquino R, Tirino V, Papaccio G (2013) Three years after transplants in human mandibles, histological and in-line holotomography revealed that stem cells regenerated a compact rather than a spongy bone: biological and clinical implications. Stem Cells Transl Med 2: 316-324.

Golding JP, Trainor P, Krumlauf R, Gassmann M (2000) Defects in pathfinding by cranial neural crest cells in mice lacking the neuregulin receptor ErbB4. Nat Cell Biol 2: 103-109.

Graham A (2003) The neural crest. Curr Biol 13: R381-R384.

Gronthos S, Mankani M, Brahim J, Robey PG, Shi S (2000) Postnatal human dental pulp stem cells (DPSCs) in vitro and in vivo. Proc Natl Acad Sci USA 97: $13625-$ 13630.

Helms JA, Schneider RA (2003) Cranial skeletal biology. Nature 423: 326-331.

Hofstetter CP, Schwarz EJ, Hess D, Widenfalk J, El Manira A, Prockop DJ, Olson L (2002) Marrow stromal cells form guiding strands in the injured spinal cord and promote recovery. Proc Natl Acad Sci USA 99: 2199-2204.

Horstadius S (1950) The mechanics of sea urchin development. Annee Biol 26: 381-398.

Huang X, Saint-Jeannet JP (2004) Induction of the neural crest and the opportunities of life on the edge. Dev Biol 275: 1-11.

Hunt P, Gulisano M, Cook M, Sham MH, Faiella A, Wilkinson D, Boncinelli E, Krumlauf R (1991a) A distinct Hox code for the branchial region of the vertebrate head. Nature 353: 861-864.

Hunt P, Wilkinson D, Krumlauf R (1991b) Patterning the vertebrate head: murine Hox 2 genes mark distinct subpopulations of premigratory and migrating cranial neural crest. Development 112: 43-50.
Izpisúa-Belmonte JC, De Robertis EM, Storey KG, Stern CD (1993) The homeobox gene goosecoid and the origin of organizer cells in the early chick blastoderm. Cell 74: 645-659.

Jacox L, Sindelka R, Chen J, Rothman A, Dickinson A, Sive H (2014) The extreme anterior domain is an essential craniofacial organizer acting through kinin-kallikrein signaling. Cell Rep 8: 596-609.

Keller R, Shih J, Sater A K, Moreno C (1992) Planar induction of convergence and extension of the neural plate by the organizer of Xenopus. Dev Dyn 193: 218-234.

Klymkowsky MW, Rossi CC, Artinger KB (2010) Mechanisms driving neural crest induction and migration in the zebrafish and Xenopus laevis. Cell Adh Migr 4: 595-608.

Kurihara Y, Kurihara H, Suzuki H, Kodama T, Maemura K, Nagai R, Oda H, Kuwaki T, Cao WH, Kamada N, Jishage K, Ouchi Y, Azuma S, Toyoda Y, Ishikawa T, Kumada M, Yazaki Y (1994) Elevated blood pressure and craniofacial abnormalities in mice deficient in endothelin-1. Nature 368: 703-710.

LaBonne C, Bronner-Fraser M (1998) Neural crest induction in Xenopus: evidence for a two-signal model. Development 125: 2403-2414.

LaBonne C, Bronner-Fraser M (2000) Snail-related transcriptional repressors are required in Xenopus for both the induction of the neural crest and its subsequent migration. Dev Biol 221: 195-205.

Laino G, d'Aquino R, Graziano A, Lanza V, Carinci F, Naro F, Pirozzi G, Papaccio G (2005) A new population of human adult dental pulp stem cells: a useful source of living autologous fibrous bone tissue (LAB). J Bone Miner Res 20: 1394-1402.

La Noce M, Paino F, Spina A, Naddeo P, Montella R, Desiderio V, De Rosa A, Papaccio G, Tirino V, Laino L (2014) Dental pulp stem cells: state of the art and suggestions for a true translation of research into therapy. J Dent 42: 761-768.

Le Douarin, NM, Kalcheim C (1999) The Neural Crest, $2^{\text {nd }}$ ed. Cambridge University Press, Cambridge, chapter 4, pp154-194.

Lumsden A, Sprawson N, Graham A (1991) Segmental origin and migration of neural crest cells in the hindbrain region of the chick embryo. Development 113: 1281-1291.

Maconochie M, Krishnamurthy R, Nonchev S, Meier P, Manzanares M, Mitchell PJ, Krumlauf R (1999) Regulation of Hoxa2 in cranial neural crest cells involves members of the AP-2 family. Development 126: 1483-1494.

Marchionni C, Bonsi L, Alviano F, Lanzoni G, Di Tullio A, Costa R, Montanari M, Tazzari PL, Ricci F, Pasquinelli G, Orrico C, Grossi A, Prati C, Bagnara GP (2009) Angiogenic potential of human dental pulp stromal (stem) cells. Int J Immunopathol Pharmacol 22: 699-706.

Marshall A (1879) Morphology of vertebrate olfactory organ. Q J Microsc Sci 19: 300-340.

Mayor R, Guerrero N, Martinez C (1997) Role of FGF and noggin in neural crest induction. Dev Biol 189: 1-12.

Monsoro-Burq AH Fletcher RB, Harland RM (2003) Neural crest induction by paraxial mesoderm in Xenopus embryos requires FGF signals. Development 130: 3111 3124. 
Morales AV, Barbas JA, Nieto MA (2005) How to become a neural crest: from segregation to delamination. Sem Cell Dev Biol 16: 655-662.

Nagoshi N, Shibata S, Kubota Y, Nakamura M, Nagai Y, Satoh E, Morikawa S, Okada Y, Mabuchi Y, Katoh H, Okada S, Fukuda K, Suda T, Matsuzaki Y, Toyama Y, Okano H (2008) Ontogeny and multipotency of neural crest-derived stem cells in mouse bone marrow, dorsal root ganglia, and whisker pad. Cell Stem Cell 2: 392-403.

Nieto MA (2001) The early steps of neural crest development. Mech Dev 105: 27-35.

Nieto MA, Bradley LC, Wilkinson DG (1991) Conserved segmental expression of Krox-20 in the vertebrate hindbrain and its relationship to lineage restriction. Development 2: 59-62.

Noden DM (1975) An analysis of migratory behavior of avian cephalic neural crest cells. Dev Biol 42: 106-130.

Noden DM (1983) The role of the neural crest in patterning of avian cranial skeletal, connective, and muscle tissues. Dev Biol 96: 144-165.

Paino F, Ricci G, De Rosa A, D’Aquino R, Laino L, Pirozzi G, Tirino V, Papaccio G (2010) Ecto-mesenchymal stem cells from dental pulp are committed to differentiate into active melanocytes. Eur Cell Mater 20: 295-305.

Paino F, La Noce M, Tirino V, Naddeo P, Desiderio V, Pirozzi G, De Rosa A, Laino L, Altucci L, Papaccio G (2014) Histone deacetylase inhibition with valproic acid downregulates osteocalcin gene expression in human dental pulp stem cells and osteoblasts: evidence for HDAC2 involvement. Stem Cells 32: 279-289.

Pierret C, Spears K, Maruniak JA, Kirk MD (2006) Neural crest as the source of adult stem cells. Stem Cells Dev 15: 286-291.

Platt JB (1893) Ectodermic origin of the cartilages of the head. Anat Anz 8: 506-509.

Platt JB (1894) Ontogenetic differentiation of the ectoderm in Necturus. Second preliminary note. Arch Mikrosk Anat Entw Mech 43: 911-966.

Platt JB (1897) The development of the cartilaginous skull and of the branchial and hypoglossal musculature in Necturus. Morphol Jb 25: 377-464.

Prockop DJ (1997) Marrow stromal cells as stem cells for nonhematopoietic tissues. Science 276: 71-74.

Rivera-Pérez JA, Mallo M, Gendron-Maguire M, Gridley T, Behringer RR (1995) Goosecoid is not an essential component of the mouse gastrula organizer but is required for craniofacial and rib development. Development 121: 3005-3012.

Saldivar JR, Sechrist JW, Krull CE, Ruffins S, BronnerFraser M (1997) Dorsal hindbrain ablation results in rerouting of neural crest migration and changes in gene expression, but normal hyoid development. Development 124: 2729-2739.

Sasaki T, Ito Y, Bringas P Jr, Chou S, Urata MM, Slavkin H, Chai Y (2006) TGFbeta-mediated FGF signaling is crucial for regulating cranial neural crest cell proliferation during frontal bone development. Development 133: 371 381 .

Sasaki R, Aoki S, Yamato M, Uchiyama H, Wada K, Okano T, Ogiuchi H (2008) Tubulation with dental pulp cells promotes facial nerve regeneration in rats. Tissue Eng Part A 14: 1141-1147.

Schilling TF, Prince V, Ingham PW (2001) Plasticity in zebrafish hox expression in the hindbrain and cranial neural crest. Dev Biol 231: 201-216.

Schiraldi C, Stellavato A, D’Agostino A, Tirino V, d'Aquino R, Woloszyk A, De Rosa A, Laino L, Papaccio G, Mitsiadis TA (2012) Fighting for territories: time-lapse analysis of dental pulp and dental follicle stem cells in co-culture reveals specific migratory capabilities. Eur Cell Mater 24: 426-440.

Sham MH, Vesque C, Nonchev S, Marshall H, Frain M, Gupta RD, Whiting J, Wilkinson D, Charnay P, Krumlauf R (1993) The zinc finger gene Krox20 regulates HoxB2 (Hox2.8) during hindbrain segmentation. Cell 72: 183-196.

Smith JL, Schoenwolf GC (1989) Notochordal induction of cell wedging in the chick neural plate and its role in neural tube formation. J Exp Zool 250: 49-62.

Stemple DL, Anderson DJ (1992) Isolation of a stem cell for neurons and glia from the mammalian neural crest. Cell 71: 973-985.

Takahashi M, Suzawa T, Yamada A, Yamaguchi T, Mishima K, Osumi N, Maki K, Kamijo R (2014) Identification of gene expression profile of neural crestderived cells isolated from submandibular glands of adult mice. Biochem Biophys Res Commun 446: 481-486.

Taneyhill LA (2008). To adhere or not to adhere: the role of Cadherins in neural crest development. Cell Adh Migr 2: 223-230.

Techawattanawisal W, Nakahama K, Komaki M, Abe M, Takagi Y, Morita I (2007) Isolation of multipotent stem cells from adult rat periodontal ligament by neurosphereforming culture system. Biochem Biophys Res Commun 357: 917-923.

Teo AK, Vallier L (2010) Emerging use of stem cells in regenerative medicine. Biochem J 428: 11-23.

Thesleff I, Sharpe P (1997) Signalling networks regulating dental development. Mech Dev 67: 111-123.

Theveneau E, Mayor R (2012) Neural crest delamination and migration: From epithelium-to-mesenchyme transition to collective cell migration. Dev Biol 366: 34-54.

Thorogood P (1989) Review of developmental and evolutionary aspects of the neural crest. Trends Neurosci 12: 38-39.

Tondeleir D, Noelanders R, Bakkali K, Ampe C (2014) Beta-actin is required for proper mouse neural crest ontogeny. PLoS One 9: e85608.

Trainor PA, Krumlauf R (2000) Patterning the cranial neural crest: hindbrain segmentation and Hox gene plasticity. Nat Rev Neurosci 1: 116-124.

Tucker AS, Yamada G, Grigoriou M, Pachnis V, Sharpe PT (1999) Fgf-8 determines rostral-caudal polarity in the first branchial arch. Development 126: 51-61.

Widera D, Grimm WD, Moebius JM, Mikenberg I, Piechaczek C, Gassmann G, Wolff NA, Thévenod F, Kaltschmidt C, Kaltschmidt B (2007) Highly efficient neural differentiation of human somatic stem cells, isolated by minimally invasive periodontal surgery. Stem Cells Dev 16: $447-460$. 
Wilson DI, Burn J, Scambler P, Goodship J (1993) Di George syndrome: part of CATCH 22. J Med Genet 30: 852-856.

Woo K, Fraser SE (1998) Specification of the hindbrain fate in the zebrafish. Dev Biol 197: 283-296.
Yamada G, Mansouri A, Torres M, Stuart ET, Blum M, Schultz M, De Robertis EM, Gruss P (1995)

Targeted mutation of the murine goosecoid gene results in craniofacial defects and neonatal death. Development 121: 2917-2922. 